\section{Multifocal Motor Neuropathy with Conduction Block Following Treatment with Infliximab}

\section{To the Editor:}

Anti-tumor necrosis factor- $\alpha$ (anti-TNF) therapy is a frequent therapeutic modality in patients with autoimmune disease. There is increased recognition that these agents may cause various inflammatory demyelinating neuropathies. We describe a 36-year-old man with Crohn's disease who developed multifocal motor neuropathy with conduction block (MMNCB) after treatment with infliximab. He was diagnosed in 1997 with severe fistulizing Crohn's disease. He was started on infliximab in hospital in February 2000 as he had not responded to treatment with azathioprine, metronidazole, and ciprofloxacin. He had 2 further infusions of infliximab in April and May 2000. On May 30, 2000, he underwent ileocolic resection. Preoperatively he reported mild hand numbness; postoperatively he developed progressive bilateral weakness of his wrists, finger extensors, and interossei as well as marked weakness in the extensors of his toes and moderate weakness of his ankle dorsiflexors. Sensation was preserved. Nerve conduction studies revealed mildly delayed ulnar F-wave latency at 32.7 $\mathrm{ms}$. The remainder of the study was normal. Conduction block was not found. Electromyography revealed reduced recruitment in muscles of the upper and lower extremity, with fibrillation potentials and positive sharp waves identified in tibialis anterior, medial gastrocnemius, extensor digito- rum, and first dorsal interosseus. The electrophysiological diagnosis was a motor neuropathy with axonal features. It was concluded that he had a polyneuropathy secondary to Crohn's or metronidazole. Infliximab was not considered as a possible cause at this time. His deficits slowly resolved without treatment over the ensuing months. In 2005 he had a further flare of his disease requiring a subtotal colectomy. Azathioprine was restarted and he received 3 further infusions of infliximab at $5 \mathrm{mg} / \mathrm{kg}$ (400 mg each), after which his disease remitted and infliximab was discontinued. His disease flared again in February 2008 and he received a further 10 infusions of $400 \mathrm{mg}$ between February 28, 2008, and July 13, 2009. On July 14, 2009, he presented to the rheumatology clinic where he had been seen twice before for nonspecific arthritic complaints, with a 3-month history of progressive left-side foot drop and bilateral wrist and hand weakness for consideration of a diagnosis of mononeuritis multiplex. His only medication was ciprofloxacin $500 \mathrm{mg}$ BID. On examination, fasciculations were present in the forearm extensor compartments and triceps bilaterally with no muscle atrophy. He had a bilateral wrist drop, worse on the left; wrist and finger extension was $0 / 5$ on the left and $1 / 5$ on the right. He had a left-side foot drop, with ankle dorsiflexion 4-/5. Both brachioradialis reflexes and the left ankle reflex were absent. Sensation was normal.

Investigations revealed a normal hemoglobin $\mathrm{A} 1 \mathrm{C}$ and normal electrolytes, renal, thyroid, and liver function. Antinuclear antibody was positive at $1 / 80($ normal $<1 / 40)$. Extractable nuclear antigens, antinuclear cyto-

Table 1. Nerve conduction studies reveal conduction block in the bilateral radial nerves.

\begin{tabular}{|c|c|c|c|c|c|c|c|c|}
\hline & \multicolumn{8}{|c|}{ Motor } \\
\hline & \multicolumn{4}{|c|}{ Left } & \multicolumn{4}{|c|}{ Right } \\
\hline & $\begin{array}{l}\text { Latency, } \\
\text { ms }\end{array}$ & $\begin{array}{l}\mathrm{CV}, \\
\mathrm{m} / \mathrm{s}\end{array}$ & $\begin{array}{l}\text { Amplitude, } \\
\mathrm{mV}\end{array}$ & $\begin{array}{c}\text { F-Latency, } \\
\text { ms }\end{array}$ & $\begin{array}{l}\text { Latency, } \\
\text { ms }\end{array}$ & $\begin{array}{l}\mathrm{CV}, \\
\mathrm{m} / \mathrm{s}\end{array}$ & $\underset{\mathrm{mV}}{\text { Amplitude, }}$ & $\begin{array}{c}\text { F-Latency } \\
\mathrm{ms}\end{array}$ \\
\hline \multicolumn{9}{|l|}{ Motor } \\
\hline \multicolumn{9}{|l|}{ Median (APB) } \\
\hline Erb's & 14 & 60 & 12.6 & & & & & \\
\hline Axilla & 8.3 & 58 & 13.6 & & 9.6 & 66.7 & 9.5 & \\
\hline Elbow & 7.1 & 55 & 14.5 & & 7.5 & 53.5 & 10.2 & \\
\hline Wrist & 2.9 & & 15.6 & 28.8 & 3.2 & & 10.5 & 25.1 \\
\hline \multicolumn{9}{|l|}{ Ulnar (ADM) } \\
\hline Erb's & 14 & 60 & 7.6 & & & & & \\
\hline Axilla & 9.2 & 54 & 8.5 & & 9.4 & 83.3 & 4.8 & \\
\hline Ab elbow & 8 & 50 & 9.2 & & 8.2 & 47.6 & 4.5 & \\
\hline Bel elbow & 5.6 & 47 & 9.7 & & 6.1 & 55.1 & 5.2 & \\
\hline Wrist & 2.6 & & 10.4 & 29.6 & 2.2 & & 5.5 & 29.3 \\
\hline \multicolumn{9}{|l|}{ Radial (EIP) } \\
\hline Plexus & 8.7 & & 2.5 & & & & & \\
\hline Ab elbow & 3 & & 2.8 & & 4.5 & 76.5 & 3.6 & \\
\hline Bel elbow & 2 & & 7.3 & & 2.8 & & 10.8 & \\
\hline \multicolumn{9}{|l|}{ Peroneal (EDB) } \\
\hline Pop fos & 12.8 & 44 & 5.6 & & & & & \\
\hline Fib head & 11.2 & 41 & 7.2 & & & & & \\
\hline Ankle & 3.8 & & 8.2 & 61.8 & & & & \\
\hline \multicolumn{9}{|l|}{ Tibial (AHB) } \\
\hline Pop fos & 11.8 & 56 & 5.4 & & & & & \\
\hline Ankle & 4.8 & & 6.6 & 55.1 & & & & \\
\hline \multicolumn{9}{|l|}{ Sensory } \\
\hline Median palm - wrist & 1.3 & 61 & 38.7 & & 1.4 & 59.3 & 55.5 & \\
\hline Median dig II - wrist & st 2.0 & & 11.8 & & 2.1 & & 25.9 & \\
\hline Radial - forearm & 1.7 & 59 & 9.8 & & 1.1 & 92.6 & 19.9 & \\
\hline Ulnar palm - wrist & 1.0 & 67 & 17.4 & & & & & \\
\hline Ulnar dig V - wrist & 1.5 & & 14.8 & & & & & \\
\hline Sural foreleg - ankle & e 2.8 & 50 & 17.4 & & & & & \\
\hline
\end{tabular}

CV: conduction velocity; F-latency: F-wave; APB: abductor pollicis brevis; ADM: abductor digiti/minimi; EIP: extensor indicis proprius; EDB: extensor digitorum brevis; AHB: abductor hallucis brevis. 
plasmic antigens, cryoglobulins, and testing for hepatitis B, hepatitis C and human immunodeficiency virus were negative. Vitamin B12, red blood cell folate levels, and serum protein electrophoresis and complements were normal. He had a microcytic anemia with hemoglobin $83 \mathrm{~g} / 1$; white blood cell count was $6.4 \times 10^{9} / 1$ with lymphopenia $0.67 \times 10^{9} / 1$ and normal neutrophil count. Platelet count was elevated at $426 \times 10^{9} / 1$. Erythrocyte sedimentation rate was elevated at $46 \mathrm{~mm} / \mathrm{h}$ (normal $0-14$ ) and high-resolution C-reactive protein was elevated at $15.5 \mathrm{mg} / \mathrm{l}$ (normal > $10 \mathrm{mg} / \mathrm{l}$ ). His antiganglioside (anti-GM1) antibodies were weakly positive at an inverse titer of 100 (negative $<100$, positive $>400$ ). Nerve conduction studies revealed conduction block at both radial nerves; sensory amplitudes and conduction velocities were normal (Table 1). He was diagnosed with MMNCB and treated with monthly infusions of intravenous immunoglobulin (IVIG). Further infliximab infusions were discontinued. His deficits gradually resolved.

MMNCB is an asymmetric motor neuropathy that develops over months to years. Diagnostic features include the presence of multifocal partial motor conduction blocks and association with anti-GM1 antibodies in $50 \%$ of cases $^{1}$. MMNCB has been rarely reported as a consequence of treatment with anti-TNF agents, usually infliximab (Table 2). In our review of the literature we found 6 other cases associated with anti-TNF therapy, and an additional 3 cases were felt to represent a similar entity, acute motor neuropathy with conduction block ${ }^{2,3}$. Other peripheral nerve lesions in patients treated with anti-TNF agents have been infrequently described and include Guillain-Barré syndrome, Miller Fisher syndrome, chronic inflammatory demyelinating polyradiculoneuropathy, mononeuropathy simplex or multiplex, and axonal sensory or sensorimotor polyneuropathy ${ }^{4}$. The literature is further confounded by the fact that many of the underlying diseases themselves may be associated with polyneuropathy; indeed, there are only 2 cases of patients with MMNCB associated with anti-TNF therapy without another plausible explanation ${ }^{5,6}$.
We believe our case is unique in that not only did the patient develop a polyneuropathy during therapy with infliximab, but he had similar symptoms during a previous course of treatment that were unrecognized. Reexposure to infliximab led to reappearance of his symptoms, which lends credence to causality. Lozeron, et al also reported a case of a patient with ankylosing spondylitis who developed paresthesias while receiving etanercept. The condition resolved with cessation ${ }^{3}$. The patient was subsequently treated with adalimumab and then infliximab, after which he developed worsening symptoms and was found to have sensorimotor polyneuropathy with conduction block. We are unable to explain why upon rechallenge it took a longer period of time for our patient's symptoms to develop; however, it may be related to a total dose effect. Another consideration is that he may have developed antibodies against infliximab, a situation that may have resulted in diminished serum levels for the same dose administered. In general, it is hypothesized that autoimmunity is responsible for the development of neuropathy related to TNF- $\alpha$ antagonist thera$\mathrm{py}^{4}$. Neuropathy that develops during anti-TNF therapy has a broad differential, and prompt discontinuation of the offending medication is often warranted. Treatment with IVIG is commonly employed ${ }^{7}$, with most patients achieving some response (Table 2).

CLAIRE E. BARBER, MD, Rheumatology Resident, University of Toronto, and Division of Rheumatology, Department of Medicine, Mount Sinai Hospital, The Rebecca MacDonald Centre for Arthritis and Autoimmune Diseases, 60 Murray St., Ste. 2-001, Toronto, Ontario M5T 3L9, Canada; PETER LEE, MD, Division of Rheumatology; A. HILLARY STEINHART, MD, Division of Gastroenterology; JASON LAZAROU, Division of Neurology, Department of Medicine, Mount Sinai Hospital, University of Toronto. Address correspondence to Dr. Barber. E-mail: claire.barber@utoronto.ca

Table 2. Summary of patients developing multifocal motor neuropathy with conduction block following treatment with anti-TNF- $\alpha$ agents. Three cases ${ }^{2,3}$ were not included as they were considered to represent acute multifocal motor neuropathy.

\begin{tabular}{lllll}
\hline Reference & Patient & Drug & Presentation & Treatment/Outcome \\
\hline 8 & 60-year-old man with RA & $\begin{array}{l}\text { Infliximab } 3 \mathrm{mg} / \mathrm{kg} \\
\text { with methotrexate } \\
\text { and prednisolone }\end{array}$ & $\begin{array}{l}\text { Developed progressive upper and } \\
\text { lower motor limb weakness } 5 \mathrm{mo}\end{array}$ & $\begin{array}{l}\text { Infliximab discontinued and IVIG } \\
\text { after treatment with infliximab. EMG+ } \\
\text { improvement. Total } 4 \text { monthly pulses }\end{array}$ \\
& & & for conduction block. Antibodies to
\end{tabular}

6

40-year-old woman with RA

Infliximab $3 \mathrm{mg} / \mathrm{kg}$ q 8 weeks Jan 2003

5

$$
\begin{gathered}
\text { 54-year-old man with AS } 10 \text { yrs } \\
\begin{array}{c}
\text { Infliximab } 2005 \\
(5 \mathrm{mg} / \mathrm{kg} / \mathrm{wk}) \mathrm{IV} \mathrm{q} \\
8 \text { weeks }
\end{array}
\end{gathered}
$$

9

$\begin{array}{lc}\begin{array}{l}\text { 34-year-old woman with } \\ \text { chronic hepatitis C, polyarthritis, }\end{array} & \text { in June } 2003 \\ \text { and cryoglobulinemia } & (3 \mathrm{mg} / \mathrm{kg})\end{array}$

10

39-year-old man with hidradenitis suppurativa

3 45-year-old man with psoriasis Infliximab $5 \mathrm{mg} / \mathrm{kg}$ 15 yrs and psoriatic arthritis 8 yrs 3 doses; changed

to etanercept for lack of effect $50 \mathrm{mg} / \mathrm{wk}$ for

6 mo; eventually changed

back to infliximab $5 \mathrm{mg} / \mathrm{kg}$ for conduction block. Antibodies to

GM-1 not tested

Oct 2003 progressive symptoms right hand. EMG definite conduction block. IgM anti-GM1+ (1:640)

June 2006 progressive weakness L hand, later R foot (drop), and R arm/ hand. EMG+ for conduction block

After 4 infusions, developed progressive weakness of both hands and $\mathrm{R}$ foot. Anti-GM1 antibodies+. EMG+ for pure polyneuropathy with conduction block Symptoms after 4 infusions. Further details not described

Had infusion reaction with last infusion and noted progressive hand weakness 8 weeks later. EMG+ for multifocal conduction block
Infliximab discontinued March 2004. Treated with IVIG for 2 days monthly with clinical and EMG improvement after 11 mo followup Infliximab stopped Dec 2006. Spontaneously improved with only mild residual weakness by October 2007

Infliximab discontinued. Treatment with IVIG (dose not reported) led to complete response within weeks

Treatment and followup not described

Infliximab stopped and treated twice with IVIG $2 \mathrm{~g} / \mathrm{kg}$ with no effect. Underwent plasma exchange $\times 4$, then treated with simultaneous IVIG and plasma exchange. Full recovery

RA: rheumatoid arthritis; AS: ankylosing spondylitis; TNF: tumor necrosis factor; EMG: electromyogram; IVIG: intravenous immunoglobulin.

Personal non-commercial use only. The Journal of Rheumatology Copyright @ 2010 . All rights reserved. 


\section{REFERENCES}

1. Van Asseldonk JT, Franssen H, Van den Berg-Vos RM, Wokke JH, Van den Berg LH. Multifocal motor neuropathy. Lancet Neurol 2005;4:309-19.

2. Singer OC, Otto B, Steinmetz H, Ziemann U. Acute neuropathy with multiple conduction blocks after TNF-alpha monoclonal antibody therapy. Neurology 2004;63:1754.

3. Lozeron P, Denier C, Lacroix C, Adams D. Long-term course of demyelinating neuropathies occurring during tumor necrosis factor-alpha-blocker therapy. Arch Neurol 2009;66:490-7.

4. Stubgen JP. Tumor necrosis factor-alpha antagonists and neuropathy. Muscle Nerve 2008;37:281-92.

5. Paolazzi G, Peccatori S, Cavatorta FP, Morini A. A case of spontaneously recovering multifocal motor neuropathy with conduction blocks (MMNCB) during anti-TNF alpha therapy for ankylosing spondylitis. Clin Rheumatol 2009;28:993-5.

6. Cocito D, Bergamasco B, Tavella A, Poglio F, Paolasso I, Costa P, et al. Multifocal motor neuropathy during treatment with infliximab. J Peripher Nerv Syst 2005;10:386-7.
7. van Schaik IN, van den Berg LH, de Haan R, Vermeulen M. Intravenous immunoglobulin for multifocal motor neuropathy. Cochrane Database Syst Rev 2005;2:CD004429.

8. Tektonidou MG, Serelis J, Skopouli FN. Peripheral neuropathy in two patients with rheumatoid arthritis receiving infliximab treatment. Clin Rheumatol 2007;26:258-60.

9. Rodriguez-Escalera C, Belzunegui J, Lopez-Dominguez L, Gonzalez C, Figueroa M. Multifocal motor neuropathy with conduction block in a patient with rheumatoid arthritis on infliximab therapy. Rheumatology 2005;44:132-3.

10. Fardet L, Dupuy A, Kerob D, Levy A, Allez M, Begon E, et al. Infliximab for severe hidradenitis suppurativa: transient clinical efficacy in 7 consecutive patients. J Am Acad Dermatol 2007;56:624-8

J Rheumatol 2010;37:8; doi:10.3899/jrheum.100072 